\title{
Exploring Factors Which Influence Travel Behavior of Bicyclists- A Case Study in Kumamoto, Japan
}

\section{Zhengming Zhu, ${ }^{2}$ RikenHomma, ${ }^{3}$ Kazuhisa Iki}

${ }^{1}$ Zhengming Zhu, Department of Architecture and Environment Planning, Graduate School of Science and Technology, Kumamoto University, Kumamoto, Japan,

${ }^{2}$ RikenHomma, Division of Environmental Science, Faculty of Advanced Science and Technology, Kumamoto University, Kumamoto, Japan.

${ }^{3}$ Kazuhisa Iki, Division of Environmental Science, Faculty of Advanced Science and Technology, Kumamoto University, Kumamoto, Japan.

Correspondence Author: Zhengming Zhu, Kumamoto University, Department of Architecture and Environment Planning, Graduate School of Science and Technology, 2-39-1 Kurokami, Chuo-Ku, Kumamoto, 860-8555, Japan.

E-mail: syusoumei@yahoo.co.jp

Received date: 23 February 2018, Accepted date: 1 April 2018, Online date: 15 April 2018

Copyright: (C) 2018 Zhengming Zhu et al. This is an open-access article distributed under the terms of the Creative Commons Attribution License, which permits unrestricted use, distribution, and reproduction in any medium, provided the original author and source are credited.

\begin{abstract}
Background: More than $12 \%$ of citizens in Kumamoto city use bicycles as primary mode of transportation in their daily lives. Hence, creating a bicycling-friendly environment is of great importance when Kumamoto City is on its way in achieving a compact city. The city government have organized a few transportation surveys, such as the 4th household travel survey, however, these surveys for bicyclists are often incomprehensive. Objectives: A site surveying through video-observation has recorded the travel behaviors of 3188 bicyclists as well as their preference in riding on the sidewalk or roadway and left side or right side. Correlation analysis method was employed to explore the factors influencing the travel behaviors of bicyclists. This study focused on four key research questions: (1) What are the constituents of bicyclists in the city? (2) Which area has the most bicycling trips, and what factors leading to it? (3) What are the differences between bicyclists riding on sidewalk and roadway, and how do land use and road condition affect the dynamics? (4) What are the differences between bicyclists riding on opposing directions on a same side, and what factors influence such differences? Results: The findings showed that, there are more male bicyclists than female bicyclists in Kumamoto City. Besides, female bicyclists prefer to ride on the sidewalk. Moreover, land use of residential, public, road and, water coverage can positively or negatively influence the bicycling volume. Road condition, such as width of sidewalk, barriers between sidewalk and roadway, and existence of bicycle lane have positive or negative impact on the preferred site for bicycling. Traffic volume of the bicycle, width of sidewalk and roadway, and pavement of sidewalk can influence the 'selection to ride on the left side or the opposite side'. Conclusion: The study found that distribution of traffic volume of bicycling is similar with the other motorized transportation which bicycling is the primary mode of transportation for daily commute in Kumamoto. The built environment and different types of land use will influence the bicycle volume whereas, and the road condition, such as width of sidewalk and traffic volume of motorway, will influence distribution of cycling volume on the left or right side. The study also observed that there are more cyclists riding on the sidewalks than motorways. In addition, bicycle lane can attract more bicycle volume away from sidewalks, which implies that the importance of designated lanes or ways special for bicycles.
\end{abstract}

Key words: Bicycling, Sidewalk, Left and right, Land use, Road construction

\section{INTRODUCTION}

Without doubt, promoting the utilization of bicycles is never out of time (Malcolm, 2014). With the popularity of encouraging programs such as public bicycle sharing systems around the world, bicycle seemingly returns to people's daily life again. Although cities such as New York (Ahmadreza and Naveen, 2016) and Melbourne (Elliot et al., 2014) have launched the bicycle sharing system, there are only a few shares of bicycling among all the transportation modes. In contrast, the majority of cities in Japan have 10\%-15\% share of using bicycles as a main transportation mode (Kobayashi, 2013). The share of bicycling in Japan at average level of developed countries. A case study of this research, found that there are about $12 \%$ of citizens in Kumamoto city use bicycles for multiple of purposes in daily life (Zhu et al., 2017).

On June 1, 2015, Japanese official revised the Road Traffic Law (2016) stated that all the bicycles should ride on the left side of the roadway. Only a few occasions below can ride on the sidewalk:

- Where there is mark saying that it is permitted to ride on the sidewalk;

- When it is dangerous to ride on the motor way for children and others;

- Other situations when you must ride in pedestrian way, ride slowly, or walk with bicycle.

This study aims to explore the following questions: "what is the current condition? Does every bicyclist follow the rules mentioned? What kind of choices these bicyclists make? What physical environments or other factors may that lead to such choices?

With the increasing study of bicycle in recent years, research on bicyclists which aims to understand their characteristics has also increased. According to the findings of Sener, Eluru, and Bhat, factors such as individual and household demographics have relationship with the decision of riding a bicycle (Ipek et al., 
2009). Jennifer and Nathan (2013) categorized four types of bicyclists. As indicated by their research, the speed of barrier between sidewalk and motor way is related with the bicycling rate. Traffic infrastructure or facility, which may promote the use of bicycle, has attracted researchers' attention. Nathan (2011) tried to assess bicycle accessibility by evaluating the types of infrastructure that increase the bikeability. Furthermore, Lisa and Michael (1998) carried out a study by comparing different situations and found that bicyclists among Toronto commuters used sidewalks primarily on high volume roads, especially with multilane. According to the survey of Guisah and Kelly (2009), bicycle lanes, trails and path will promote the use of bicycles. Additionally, Iderlina $e t$ al. (2016) researched the effect on the use of bicycle sharing from natural and built environment. There are also various topics on bicycling related research in Japan. Okada and Yoshida (2014) observed that bicycle volume on the sidewalks have brought safety problems and they stated that the individual knowledge,experiences of bicyclists influence the behavior of path choice. Most of the studies mentioned above focused more on the aspect of safety and accident analysis. Currently, there are very few studies discussed on the topics related to bicycling infrastructure. Since Japan is a country with large number of bicyclists, it is of great necessity to conduct research on the infrastructure and environment for bicycling. The case study area in this study, the Kumamoto city, is on the direction of improving the bicycling environment. Hence, it is important to adopt bicycling infrastructure-related research from cities overseas and enforce it with Japanese examples as our target surveying group. This research is just a start to focus on the planning of bicycle infrastructure. The authors will try to explore more detail and research in the future.

\section{Case Study In Kumamoto City, Japan:}

As one of the most important cities in Kyushu island of Japan, Kumamoto city has a population of about 740,000 citizens. The city is in a basin surrounded by mountains in three sides and Ariake Sea from the west side. The city covers five administrative wards, in which two have the largest inhabitants albeit with the least surface area.

According to the 2012 Household Travel Survey of Kumamoto Metropolitan Area in Kumamoto, there are more than 12\% of citizens use the bicycle as their main transportation mode in weekdays (5), and it ranks in the middle level among all the main cities in Japan. To create a favorable urban environment, the local government has set 21 parking spaces for 5159 bicycles in the downtown area since 2012. Recently, other bicycle related infrastructures such as separated bicycle path and non-separated bicycle lane, have been increasing in the city. Since there is no new travel survey after 2012, the influence of these newly-constructed bicycle infrastructure has not been proven.

\section{(1) Objectives:}

Based on four key research questions, this study explores the factors that influence the travel behavior of bicyclists in Kumamoto City.

1. What are the constituents of the bicyclists in the city, or what kinds of citizens ride a bicycle?

2. Which area has the most bicycling trips traffic volume, and what factors leading to it?

3. What are the differences between bicyclists riding on sidewalk and motorway for motor vehicles, and how do land use and road condition affect the dynamics?

4. What are the differences between bicyclists riding on the opposing directions on the same side, and what factors influence such differences?

(2) Data and methodology:

The analysis of this study is based on three important data resources: 1. Video-based survey data, 2. Land Use Survey Data of Kumamoto City in 2012 , and 3. information of road and sidewalk collected from different sources.

The authors collected the video-based survey data in April and May 2017 by using video-camera (Sony FDR-AX40) to shoot videos along the sidewalk to collect behavior data of cyclists. During the time from 15:00 to 19:00 of April 18th, 19th, 20th, 25th, 27th, May 1st and 2nd, 2017, the authors recorded a total of 1430-minute video at 96 observation places. The 96 observation places in 48 sites were selected randomly based on different road constructions. They kept a 5minute video as a survey unit and recorded 2-6 units at every observation place.

The authors collected data on site surveying and checked the accuracy by watching videos again. Authors obtained effective information of 3188 bicyclists as well as the following data of every cyclist:

a. Gender: male or female.

b. Age: students, young people or middle-aged and the elderly people. Since guess the correct age of every bicyclist from the video was not feasible, the authors classified bicyclists into three age categories. Japanese students in elementary, middle, and high schools wear school uniforms on weekdays, it is thus easy to distinguish them from the videos. Young people are mainly students in colleges and university. The others are in the category of middle-aged and the elderly group. When it became difficult to recognize the age of bicyclists, the authors classified them based on their clothes, the type of bicycle, and the bicycling speed.

c. Whether the bicyclists rode the bicycle in the opposite direction or not.

d. Where did the bicyclists ride the bicycle, on the sidewalk, bicycle lane, or road for motor vehicles?

e. The volumes of motor vehicles in each survey unit.

The authors applied the Land Use Survey Data of Kumamoto City in 2012 from Department of Civil Engineering of Kumamoto City Government. These data were GIS shapefile of different types of land use. Furthermore, the authors created buffers of $500 \mathrm{~m}$ and $1000 \mathrm{~m}$ around each observation place and calculated the area of residence, commerce, industry, public space, water coverage, and et cetera.

Table 1: Different Types of Data Used in the Study

\begin{tabular}{|l|l|}
\hline Type of data & Description \\
\hline Bicycling volume & Average bicycling volume in 5 minutes \\
\cline { 2 - 3 } & Average bicycling volume in 5 minutes on the left side sidewalk \\
\cline { 2 - 3 } & Average bicycling volume in 5 minutes on the left side roadway \\
\cline { 2 - 3 } & Average bicycling volume in 5 minutes on the right-side sidewalk \\
\cline { 2 - 3 } & Average bicycling volume in 5 minutes on the right-side roadway \\
\hline \multirow{5}{*}{ Land use } & $\begin{array}{l}\text { Area of residential, shared residential, public, commercial, industrial, water coverage, road land use in 1000m buffer of an } \\
\text { observation place }\end{array}$ \\
\cline { 2 - 3 } & $\begin{array}{l}\text { Area of residential, shared residential, public, commercial, industrial, water coverage, road land use in 500m buffer of an } \\
\text { observation place }\end{array}$ \\
\cline { 2 - 2 } & Width of sidewalk \\
\cline { 2 - 3 } & Width of roadway \\
\cline { 2 - 3 } & Existence of bicycle lane (when the space between a sidewalk and a roadway is wider than $0.5 \mathrm{~m}$, yes; less than $0.5 \mathrm{~m}$, no) \\
\cline { 2 - 3 } & $\begin{array}{l}\text { Barriers between sidewalk and roadway (when there are continuous trees, flower beds, or steps within } 100 \mathrm{~m} \text { of the } \\
\text { observation place, yes; another situation is no) }\end{array}$ \\
\cline { 2 - 3 } & Pavement of sidewalk (asphalt or brick) \\
\hline Traffic volume & $\begin{array}{l}\text { Average volume of motor vehicles in 5 minutes of a roadway, if the roadway has multilane, the authors count the volume } \\
\text { of the traffic volume in the lane next to sidewalk }\end{array}$ \\
\hline
\end{tabular}


Information of road and sidewalk were partly downloaded from the OpenStreetMap and partly collected from the site surveying. The data of each observation was collected in the following types: width of the sidewalk, width of bicycle lane if it exists, width of the roadway for motor vehicles, the pavement of sidewalk, and et cetera.

To address each of the research questions, the authors adopted several quantitative methods in this study.

1. To summarize the demographics of bicyclists by statistical classification, including gender and age information of all the bicyclists, the authors made a comparison with the past survey. Furthermore, behaviors of riding a bicycle on the sidewalk or motorway and riding a bicycle on the correct side (left side) or wrong side (right side) of the road were summarized to demonstrate the characteristics of bicyclists in Kumamoto.

2. To explore the impact of physical and non-physical environment on the volume of bicycling trips, the authors utilize the correlation and aggregate logit regression model to analyze the factors influencing the total bicycling volume of every observation place. All the data was aggregated into groups according to the observation places from this step. Physical environment factors, such as land use data and physical information of roadway (Table 1), were used as the independent variables. Additionally, the volume of bicycle trips was regarded as a dependent variable in the regression analysis.

3. To explore the factors influencing the route choice of sidewalk or motorway, both aggregate bicycling trips on the left side of sidewalk and roadway at one observation place were used in this part. The authors check the correlation between the choice of route and the environment factors, especially information of road construction (e.g. width of the sidewalk, as well as the barrier between sidewalk and roadway). What is more, variable factors, such as the volume of vehicles in 5minute unit and the volume of bicycling trips in the opposite direction, were discussed (Table 1).

4. Although it is illegal to ride on the right side, there are still a considerable number of bicyclists riding on this side, which may bring about safety problems. To explore the factors influencing the route choice of riding on the left (correct) side or right side, the authors use the similar method in step 3. Moreover, both aggregate bicycling trips of the same direction on both left and right side of sidewalks at a pair of 2 observation places were used in this part. Factors correlated to this kind of difference will also be discussed. Beyond that, comparison between riding a bicycle on right-side sidewalk and roadway was made (Table 1).

Findings:

(1) Demographics of Bicyclists in Kumamoto:

Among the data collected from site surveying, the authors found that there are more male bicyclists than female bicyclists in Kumamoto City. As for ages, young people, especially male bicyclists, constitute the largest proportion which is about $27.4 \%$ (Fig. 1). Compared with other age groups, the difference in gender of bicyclists is less obvious. This finding is contradicted to the previous study in Japan. As shown by (5), there are more female bicyclists than male bicyclists according to the household travel survey in Japan. Indeed, the data collected in this survey is concentrated on a period from $3 \mathrm{pm}$ to $7 \mathrm{pm}$, which is the time for returning home after school or work. Females in Japan are often housewives after marriage. Thus, they are more likely to use bicycles for personal purposes rather than for commuting. As a result, there are more male bicyclists observed in this study.

From the Fig. 2, the authors found that there are more bicycles riding on the sidewalk, but not on the roadway. Besides, female is more likely to ride on the sidewalk, although the new Act clearly states that bicycling on the right-side sidewalk is illegal. In contrast, male bicyclists are about twice than female bicyclists to ride on the roadway.

According to the site surveying, the authors calculated the average volume in every survey unit ( 5 minutes) and found that the volume of bicycling trips varies gradually (Fig. 3). The trips volume of bicycling increased at the beginning and reached the first peak after $4 \mathrm{pm}$. In general, university students finish the classes in the afternoon at around $4 \mathrm{pm}$, and bicycles will be the important transport mode for them to return home or going for part time work. Since late afternoon after $5 \mathrm{pm}$ is the time for the workers and high school students to return home, the bicycling volume increased again and maintained so until $7 \mathrm{pm}$.

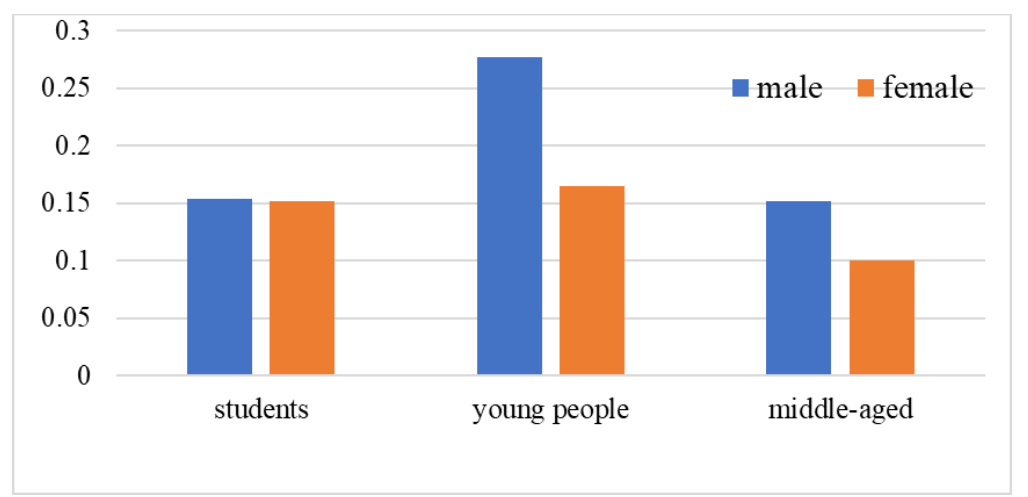

Fig. 1: Gender and age distribution of bicyclists

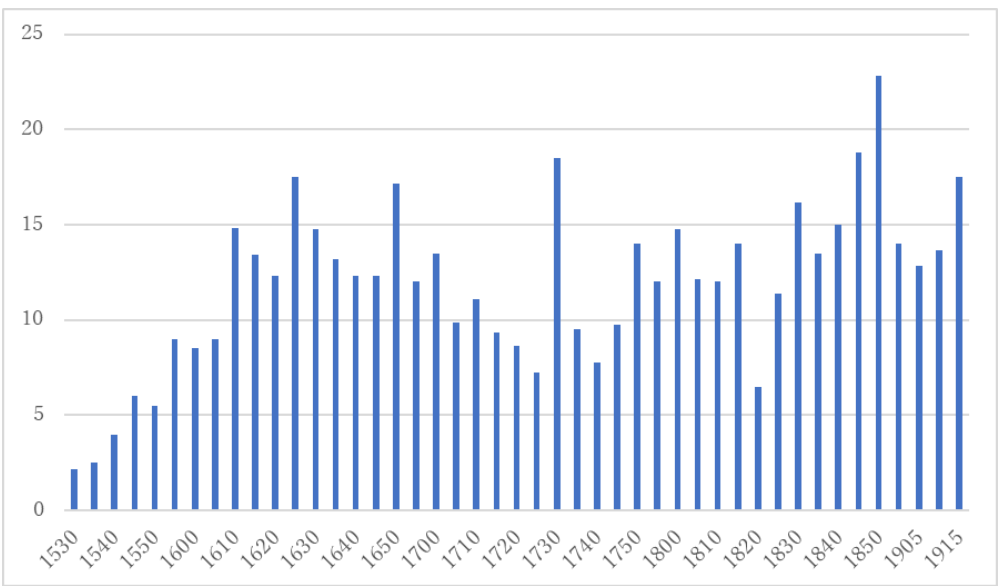

Fig. 2: Proportion of four types of bicycling position on gender 
Citation: 1Zhengming Zhu, 2RikenHomma, 3Kazuhisa Iki, 2018. Exploring Factors Which Influence Travel Behavior of Bicyclists- A Case Study in Kumamoto, Japan. Australian Journal of Basic and Applied Sciences., 12(4): 33-39.

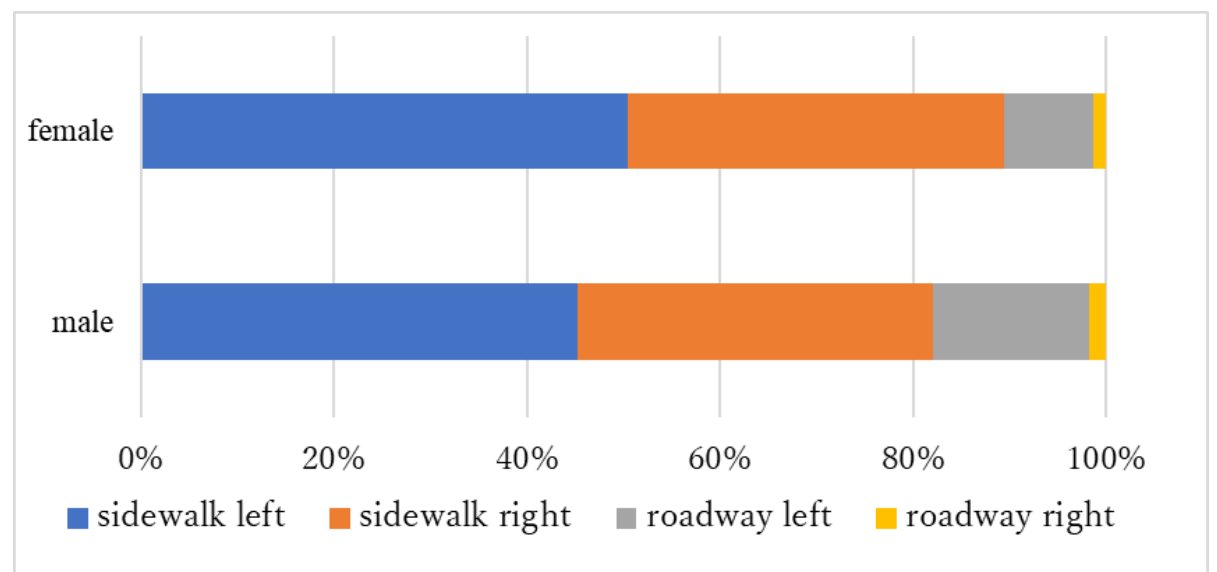

Fig. 3: Average bicycle volume in 5 minutes between 15:30 pm-19:15 pm

(2) Factors increasing bicycling volume:

It is of great significance to understand what factors may increase the utilization of a bicycle. In this part, the authors used two groups of physical environment factors to explore the keys for solving the problem: the group of land use factors and information of road construction.

a) Land use:

Different types of land use may exert different effects on various transport modes. The volume of bicycle trips is also influenced by the land use, such as residential and commercial land use. In this study, the authors found that observation places at an area with more public, residential, density roads and less water coverage may have larger number of bicycling trips (Table 2).

Public land use includes schools, universities, hospitals, city hall, and other non-for-profit facilities. In the above part, students and young people (especially university students) are regarded as the important parts of bicyclists in Kumamoto City. This justifies the reason why there are more bicyclists concentrated in this area.

Residential area includes typical residential and shared residential land use. To be specific, typical land use stands for the traditional single-family dwellings, whereas shared residential land use represents the land for mansion, dormitory, and other types of housing which are more popular among younger generations. As shown in the results, residential (especially shared residential areas) can positively influence the volume of bicycling trips. Since most of the residents in the shared residential area are young students, and the volume of bicycling trips is predictably higher.

The type of road land use can be regarded as a concept of road density. The bigger the density, the better the accessibility. The bicycle is convenient for short time trips. Here, the road land use in $500 \mathrm{~m}$ buffer of the observation places proved it again.

As shown in the results, land use of water coverage exerts a negative effect on the use of bicycle. This type of land use mainly represents the area around Shirakawa River in Kumamoto city. Where there is a river, there is a bridge. The upscale climb before crossing the bridge is definitely not a pleasant activity. Thus, this negative impact is justifiable.

b) Road construction:

Bicycle, as one of the transportation mode, is naturally related with road construction naturally. Two types of factors are considered here: (1) continuous variables, such as the width of sidewalk and the width of roadway; (2) category variables, such as the pavement of sidewalk, absence or presence of barriers between sidewalk and roadway, and absence or presence of bicycle lane.

In the aspect of continuous variables, the authors found that the width of sidewalk has a positive impact on bicycle volume. In Kumamoto city and other middle-size cities in Japan, there are only few bicycle lanes. Indeed, citizens used to ride on the sidewalk and the width of the sidewalk is still appealing to bicyclists here. Generally, the wider the road, the larger the traffic volume. The width of roadway indicates the volume of motor vehicles. Although bicycles and motor vehicles are two different types of transportation mode, both follow the characteristics of transportation. To a certain extent, they may have similar trait. It is comprehensible that the width of roadway is correlated with the bicycle volume. However, the necessity of increasing the width of roadway and the findings of categories variables will be discussed later in this manuscript.

Table 2: Correlation between factors and average bicycle volume in an observation place

\begin{tabular}{|l|l|l|}
\hline & Sidewalk & \multicolumn{2}{|l|}{} \\
\hline & Pearson correlation coefficient & $<$-value for correlation coefficient \\
\hline Width of sidewalk & $0.484^{* *}$ & $<0.01$ \\
\hline Width of roadway & $0.367^{* *}$ & $<0.01$ \\
\hline Barriers between sidewalk and roadway & $0.276^{* *}$ & $<0.05$ \\
\hline Residential area in 1000m buffer & $0.245^{*}$ & $<0.01$ \\
\hline Shared residential area in 1000m buffer & $0.294^{* *}$ & $<0.01$ \\
\hline Water coverage area in 1000m buffer & $-0.300^{* *}$ & $<0.05$ \\
\hline Public land use area in 1000m buffer & $0.208^{*}$ & $<0.05$ \\
\hline Road area in 500m buffer & $0.256^{*}$ & \\
\hline
\end{tabular}

Samples N=92

** Statistically significant valve $(\mathrm{p}<0.01)$

* Statistically significant valve $(\mathrm{p}<0.05)$

(3) Riding on the sidewalk or roadway:

According to the Road Traffic Act (2016), bicycles can be regarded as light vehicles. In principle, the bicycles should ride on the left side of a roadway. However, the authors found that about $85.1 \%$ bicyclists ride on the sidewalk in Kumamoto city, contrary to the expectation of government. Here, interpretation of the result of correlation analysis may explain some reasons of this phenomenon (Table 3). 
a) Width of sidewalk:

As demonstrated in the results, the width of sidewalk has a positive correlation with the volume of bicycling trips implies that the bicyclists prefer wider space. In Kumamoto city, only a few areas are equipped with bicycle lanes. Most citizens still ride on sidewalk, especially when the sidewalk is wide enough to ride a bicycle. This sizeable proportion of bicyclist riding on sidewalk could be due to the fear of potential risk of accidents with motor vehicles on the roadway.

b) Width of roadway (Numbers of lanes on roadway):

The second factor which may increase bicycling volumes on the sidewalk is the number of lanes on a roadway. In general, the more number of lanes on a roadway, the wider the roadway and hence the greater traffic volume. Here, the numbers of lanes on roadway is positively correlated with the bicycling volume This correlation is significant at the $\mathrm{p}=0.01$ level. Although the volume of vehicles doesn't have an obvious relationship with the preference on riding on sidewalk or roadway, the fixed expression that wider streets are more dangerous will lead to the previous situation.

\section{c) Barriers between sidewalk and roadway:}

The authors divided the situation of barriers between sidewalk and roadway into two categories: (1) the situation where there are no continuous trees, flower beds, or steps between two parts is in category $0 ;(2)$ the other situation is in category 1 . As shown in the results, the barrier is positively correlated with the bicycling volume on a sidewalk. Trees and flower beds with a high density between sidewalk and roadway can serve as a divider for a separated space for pedestrians, which is also appealing to bicyclists. Meanwhile, the other physical barriers such as steps, especially long steps between sidewalk and roadway, will decrease the probability of changing the route from sidewalk to the left side of roadway even there is enough space for a bicycle to ride on the roadway.

\section{d) The existence of bicycle lane:}

The authors attempted to explore more possible factors which will attract more bicyclists to ride on the left side of the roadway rather than on the sidewalk. However, only the existence of bicycle lane shows a positive correlation with the volume of bicycling trips on a roadway. Until now, there are only about $3 \mathrm{~km}$ roads colored in blue representing bicycle lanes in Kumamoto city. With the exception of the bicycle lanes on the Kogai Bridge, majority of these roads are not separated with the roadway. In this study, the authors regarded the road with over a $0.5 \mathrm{~m}$-width between sidewalk and roadway as the bicycle lane.

Obviously, this finding implies that the presence of a bicycle lane as one of the most encouraging factor for Kumamoto citizens to not riding on a sidewalk. A well-equipped bicycle lane, with painting or marks, will alert those who ride on a sidewalk to change their route. Even though the positive correlation value is not the strongest, the authors believe that the length limit of bicycle lane could be the reason. If there is a continuous net of bicycle lane, it will not only attract bicyclists on the sidewalk but also stimulate citizens who are using other transportation modes at present.

Table 3: Correlation between factors and bicycling volume on sidewalk or roadway in an observation place

\begin{tabular}{|c|c|c|c|c|}
\hline & \multicolumn{2}{|l|}{ Sidewalk } & \multicolumn{2}{|l|}{ Roadway } \\
\hline & Pearson correlation coefficient & $\begin{array}{l}\text { P-value for correlation } \\
\text { coefficient }\end{array}$ & $\begin{array}{ll}\begin{array}{l}\text { Pearson } \\
\text { coefficient }\end{array} & \text { correlation } \\
\end{array}$ & $\begin{array}{l}\text { P-value for correlation } \\
\text { coefficient }\end{array}$ \\
\hline Width of sidewalk & $0.393^{* *}$ & $<0.01$ & 0.012 & 0.912 \\
\hline Width of roadway & $0.407 * *$ & $<0.01$ & -0.045 & 0.669 \\
\hline Existence of bicycle lane & -0.117 & 0.266 & $0.335^{* *}$ & $<0.01$ \\
\hline $\begin{array}{l}\text { Barriers between sidewalk } \\
\text { and roadway }\end{array}$ & $0.251^{*}$ & $<0.05$ & -0.006 & 0.953 \\
\hline
\end{tabular}

Samples N=92

** Statistically significant valve $(\mathrm{p}<0.01)$

* Statistically significant valve $(\mathrm{p}<0.05)$

Table 4: Correlation between factors and bicycle volume on sidewalk or roadway of an observation place

\begin{tabular}{|l|l|l|l|l|}
\hline & Left side & Right-side \\
\hline & Pearson correlation coefficient & $\begin{array}{l}\text { P-value for correlation } \\
\text { coefficient }\end{array}$ & $\begin{array}{l}\text { Pearson correlation } \\
\text { coefficient }\end{array}$ & $\begin{array}{l}\text { P-value for correlation } \\
\text { coefficient }\end{array}$ \\
\hline Width of sidewalk & $0.335^{* *}$ & $<0.01$ & $0.291^{* *}$ & $<0.01$ \\
\hline Width of roadway & $0.226^{*}$ & $<0.05$ & $0.230^{*}$ & $<0.05$ \\
\hline Pavement of sidewalk & -0.167 & 0.123 & $-0.219^{*}$ & $<0.05$ \\
\hline $\begin{array}{l}\text { Volume of bicycle in left } \\
\text { side }\end{array}$ & 1 & & $0.452^{* *}$ & $<0.01$ \\
\hline $\begin{array}{l}\text { Illegal volume of bicycle in } \\
\text { left side }\end{array}$ & 0.053 & 0.63 & $0.316^{* *}$ & $<0.01$ \\
\hline
\end{tabular}

\section{Samples N=92}

** Statistically significant valve $(\mathrm{p}<0.01)$

* Statistically significant valve $(\mathrm{p}<0.05)$

\section{(4) Riding on the left or right side:}

Although riding on the right side of the roadway is illegal, there are about $39.3 \%$ bicyclists choose to ride on the right side. Notably, riding on the right side which is opposing the traffic may lead to a number of safety issues. Both pedestrians and bicyclists face the risk to lose their lives in a motor-vehicle accident. In 2016, among 684 bicycle-related accidents, 52.8\% accidents were due to conflict with others vehicle at a crossing (i.e. the most dangerous place for bicyclists riding on the right side). This is because generally, drivers or pedestrians pay attention to their left side at first during crossing. The following factors show the relationship with the reason why bicyclists ride on the right side (Table 4).

a) Bicycle volume on left side:

As revealed in the results, the bicycle volume on the left side has a moderate positive correlation with the volume of bicycling volume on the right side. When the bicycle volume is increasing on the left side, the probability of illegally riding a bicycle on the right side will be increasing simultaneously. Similar to motor vehicles, the bicycling trips have rush hours in the morning and evening. This phenomenon will lead to the gathering bicycle volumes in the same period. For example, during rush hours in the evening, most trips are heading toward residential area from downtown area because it is the time to return home. Since large number of trips are in the same direction, it will decrease the riding speed. Hence, the number of bicyclists who illegally ride on the right side would also increase.

\section{b) Illegal bicycle volume on left side:}

Interestingly, the result in this part shows that those who ride on the opposite side also do not like the others who do the same thing with them. When a bicyclist on the left side meets an increasing number of bicyclists riding on the opposing direction, he or she may also go to the right side of a roadway. This vicious cycle of illegal behavior will eventually lead to an unsafe road environment. Proper policy need to be enforced to avoid such situation. 
c) Width of sidewalk:

There is a positive correlation between the width of sidewalk and both bicycle volume on the left and right side. Indeed, the impact on the bicycle volume of the left side will be slightly stronger than that on the right side. Sidewalk with sufficient width will attract not only cyclists from a roadway but also those who will ride on the opposite side. Spacious sidewalk can reduce a person's vigilance on personal safety without realizing that they are threats to others.

d) Width of roadway:

Similar to the above factor, the width of roadway also affects both behaviors of riding on the left and right side. To a certain extent, the width of roadway exerts different degree of difficulty in crossing the road. A wider roadway requires longer time to wait and cross. Those who should cross the road to ride on the left side may then choose not to cross the road anymore but just ride on the right side instead. According to the finding of the authors, the width of roadway also has a moderate relationship with bicycling volume on the left side. Therefore, the width of roadway should be further discussed in the future. It is reasonable to believe that proper width of a road or a street is able to not only increase bicycling volume on left side but also decrease illegal bicycling behavior.

\section{e) The most dangerous behavior:}

During the site survey, the authors found one of the most dangerous riding behaviors: riding a bicycle on the right side of the roadway. According to the transportation law, such behavior is strictly forbidden. Although the volume is relatively small (51 trips, $1.6 \%$ ), people should be aware of such dangerous behavior. About half of this type of trip concentrates at three observation places: two of them are close to the crossings, and the remaining one is under construction within 100 meters. The government need to strengthen the penalty to curb such illegal bicycling behavior at the crossing of the road in order to deliver warning to the offenders.

\section{Conclusions:}

In this survey, the authors found that there are more female bicyclists than males in Kumamoto city, which is contradict to previous studies in Japan. However, the number of male bicyclists seems to surpass female bicyclists in a certain period of the day. The distribution of bicycle trips mimics a wave between 3 pm to 7 $\mathrm{pm}$. Volume of trips increases twice, which is the time after class, school and work time, or time for part-time job. Like the other transportation modes, bicycle volume also possesses the characteristic of a traffic peak. The results showed that the distribution of traffic volume of bicycling is similar to the other motorized transportation, which indicates that bicycling is used as daily transportation mode for commuting in Kumamoto. The establishment of bicycle related facilities will not only benefit the existing cyclists, but at the same time attract more citizens to utilize bicycles as their main transportation tools.

Types of land use influence the distribution of bicycling volume. Land use variables include public land use, residential land use, road land use, and water coverage. The former three factors have a positive impact on bicycling trips, while water coverage plays a negative role in increasing volume on bicycling trips. Citizens work in the governments sectors, or students prefer to use bicycles than others. In this study, the type of residential land use, especially the shared residential land use has a comparatively positive correlation with the bicycle volume. This finding indicates that bicycle is popular among low-income group because the bicycle it is more affordable compared to other motorized vehicles. By providing a friendly bicycling environment, their daily commuting experiences could be improved.

As demonstrated in the data, bicyclists prefer to ride on a sidewalk, albeit the New Act issued in June 2016 clearly stated that bicyclists should ride on the left side of a roadway. There are more than $85 \%$ bicycle users still choose to ride on the sidewalk rather than on the roadway. Compared to male cyclists, female cyclists are more inclined to ride on sidewalks. Wider sidewalk, multiples lanes on a roadway and pavement of brick on a sidewalk are among the attracting factors for increasing numbers of bicyclists to ride on the sidewalk. In this study, only the existence of bicycle lane on a roadway seems to be able to attract more bicyclists to not to ride on a sidewalk. It is a huge task to create a well-organized network of bicycle lane. This is due to most of the roads in Kumamoto city are too narrow to be broadened, making it difficult to implement such plan. However, Kumamoto city has initiated this plan in recent years. In addition, the authors agree that there are more bicyclists riding on the sidewalks than motorways. Bicycle lane can attract more bicycle volume away from sidewalks, which demonstrates that the importance of increasing designated lanes for bicycles.

The built environment and different types of land use will influence the bicycle volume, whereas road conditions, such as width of sidewalk and traffic volume of motorway, will influence distribution of bicycling volume on the left or right side. Two variables related to independent bicycle volume demonstrate part of the reasons why there are more than 39\% bicyclists riding on the right side. Bicycle volume on the left side has a positive correlation with the bicycle volume on the right side. An illegal bicycling trip (opposing direction) on the left side of the sidewalk will cause an increasing number of cyclists to ride on the right side of the sidewalk. A wider sidewalk is appealing to bicyclists to ride in both left and opposite direction. Policy-makers should understand the importance of proper width of sidewalk and roadway can redistribute the bicycle volume. Meanwhile, the behavior of riding a bicycle in the opposite direction of a roadway was also observed through the videos. Compared to riding in the opposite direction of a sidewalk, this behavior is much more dangerous. Hence, the authors urge the authorities to enforce stricter penalty to the offenders in the hope to curb such irresponsible bicycling behavior that could endanger the lives of other citizens.

\section{ACKNOWLEDGEMENTS}

This work was partly supported by the China Scholarship Council (file NO.201508050030). And the authors were grateful to Prof. Shoshi Mizokami for his advice on this research.

\section{REFERENCES}

Ahmadreza, F.I. and E. Naveen, 2016. Incorporating the Impact of Spatio-Temporal Interactions on Bicycle Sharing System Demand: A Case Study of New York Citibike System. Journal of Transport Geography, 54: 218-227.

Elliot, F., W. Simon, H. Narelle and M. Armando, 2014. Barriers to Bikesharing: An Analysis from Melbourne and Brisbane. Journal of Transport Geography, 41: 325-337

Guisah, A. and C. Kelly, 2009. Influence of Individual Perceptions and Bicycle Infrastructure on Decision to Bike. Transportation Research Record: Journal of the Transportation Research Board, 2140: 165-172.

Iderlina, M., B. Richard, C. Jonathan and P. Dorina, 2016. How Does Our Natural and Built Environment Affect the Use of Bicycle Sharing? Transportation Research Part A, 94: 295-307.

Ipek, N.S., E. Naveen and R.B. Chandra, 2009. Who Are Bicyclists? Why and How Much Are They Bicycling? Transportation Research Record: Journal of the Transportation Research Board, 2134: 63-72.

Jennifer, D., and M. Nathan, 2013. Four Types of Cyclists? Examination of Typology for Better Understanding of Bicycling Behavior and Potential. Transportation Research Record: Journal of the Transportation Research Board, 2387: 129-138.

Kobayashi, H., 2013. Documentation of 32th Meeting of Transportation Facility Management (in Japanese). Department of Transportation, Japan, http://www.mlit.go.jp/sogoseisaku/soukou/soukou-magazine/rennraku7.1.pdf

Lisa, A., and A. Michael, 1998. Sidewalk Bicycling Safety Issues. Transportation Research Record: Journal of the Transportation Research Board, 1636: 7176.

Malcolm, J.W., 2014. History, Risk, Infrastructure: Perspectives on Bicycling in the Netherlands and the UK. Journal of Transport \& Health, 1: 243-250. 
Citation: 1Zhengming Zhu, 2RikenHomma, 3Kazuhisa Iki, 2018. Exploring Factors Which Influence Travel Behavior of Bicyclists- A Case Study in Kumamoto, Japan. Australian Journal of Basic and Applied Sciences., 12(4): 33-39.

Nathan, M., 2011. Bikeability and the 20-min Neighborhood How Infrastructure and Destinations Influence Bicycle Accessibility. Transportation Research Record: Journal of the Transportation Research Board, 2247: 53-63.

Okada, T. and N. Yoshida, 2014. Analysis of Road Traffic Conditions and Individual Knowledge and Experiences on Cyclists Path Choice Behavior, Journal of JSCE, 70(5): 655-661.

Road Transportation Law (in Japanese) http://law.e-gov.go.jp/htmldata/S35/S35HO105.html

Zhu, Z., R. Homma and K. Iki, 2017. Exploring the Characteristic of Cycling Behavior through PT Survey. Proceeding of International Workshop on Environmental\& Architectural Design for Sustainable Development, pp: 295-307. 